\title{
Pengembangan Sistem Informasi Perpustakaan Dengan Internet Of Thing Menggunakan Perangkat Radio Frequency Identification Berbasis NodeMCU
}

\author{
Eko Pramono \\ Universitas Bina Sarana Informatika \\ Indonesia \\ eko.eop@bsi.ac.id
}

\author{
Maliah Andriyani \\ Universitas Buana Perjuangan \\ Karawang, Indonesia \\ if16.maliahandriyani@mhs.ubpkarawang.ac.id
}

\author{
Jamaludin Indra \\ Universitas Buana Perjuangan \\ Karawang, Indonesia \\ Jamaludin.indra@ubpkarawang.ac.id
}

\begin{abstract}
Abstrak-
Pengelolaan sirkulasi buku pada perpustakaan UBP Karawang telah menggunakan sistem manajemen perpustakaan yang bersifat open source. Sirkulasi buku sering kali tidak berjalan baik karena sering terjadi kehilangan buku. Susunan buku pada rak tidak berdasarkan klasifikasinya, terjadi antrean saat proses peminjaman dan pengembalian buku. Maka penelitian ini dibuat berdasarkan perkembangan teknologi saat ini banyak yang dikembangkan salah satunya yaitu Radio Frequency Identification (RFID). Pengembangan sistem informasi dengan perangkat RFID akan meningkatkan kualitas pelayanan. Mengatasi antrean yang terjadi pada peminjaman dan pengembalian buku lalu dapat mengidentifikasi buku pada rak. Perancangan alat RFID sebagai masukan dan NodeMCU melakukan proses pembacaan lalu memperoleh keluaran berupa informasi pada tag RFID. Aplikasi pengembangan sistem untuk membantu melaksanakan proses sirkulasi buku juga menjadi output dalam sebuah perancangan. Terdapat teknologi Internet Of Thing berfungsi untuk mentransfer data melalui jaringan. Merancang web application development dan web application existing dilengkapi dengan penerapan Client URL (URL) untuk menerima dan mengirim data. Pengembangan sistem informasi dengan IOT menggunakan perangkat RFID berbasis NodeMCU untuk proses pendataan buku baru, peminjaman buku dan pengembalian buku. Sistem dan perangkat alat dilakukan berdasarkan dengan prosedur penelitian dan memperoleh hasil bahwa teknologi IOT dengan perangkat RFID dan NodeMCU berhasil diterapkan pada sistem informasi perpustakaan. Keberhasilan pembacaan tag sebesar $72,22 \%$.
\end{abstract}

\section{Kata kunci - CURL, IoT, NodeMCU, RFID, Sistem Manajemen Perpustakaan}

\section{PENDAHULUAN}

Perpustakaan merupakan sebuah tempat untuk mencari dan mengembangkan informasi melalui media buku yang dikelola dan tersimpan pada rak-rak yang tersedia [1]. Penyusunan buku, pendataan buku, peminjaman dan pengembalian buku di perpustakaan menjadi fokus utama agar menjaga keseimbangan sirkulasi buku [2]. Berdasarkan observasi dan wawancara yang dilakukan pada perpustakaan UBP Karawang telah menggunakan sistem manajemen perpustakaan dalam melakukan pengelolaan sirkulasi buku. Terdapat pengembangan sistem informasi perpustakaan pada masa ini dan masa depan akan meningkatkan kualitas pelayanan dalam melakukan pengelolaan sirkulasi buku [3].

Penelitian terkait telah dilakukan oleh Primadhasa [4], perancangan aplikasi perpustakaan mempunyai empat bagian yaitu menu admin, buku tamu, menu transaksi dan alarm berbasis RFID. Peminjaman buku dilakukan dengan RFID dan sebagai sistem keamanan yang berfungsi untuk mengidentifikasi buku yang dibawa keluar dari perpustakaan tanpa melalui proses peminjaman. Penelitian berikutnya oleh Pratiwi [5], menggunakan RFID untuk membantu pengunjung mengembalikan buku pada rak yang tepat dengan disematkannya RFID dan Auto Guided Vehicle (AGV). Hasil pengujian bahwa dalam pembacaan sensor terdapat kesimpangan jarak sampai $4,1 \mathrm{~cm}$. Pembacaan tag dengan pengukuran jarak tidak mempengaruhi waktu selama masih dalam rentang jarak berdasarkan ketentuan. Selanjutnya penelitian oleh Paratama et al [6], meningkatkan efisiensi peminjaman buku dengan mengimplementasikan penggunaan RFID pada layanan self loan. Metode ini mengatasi terjadinya antrean saat proses peminjaman dan pengembalian buku. lalu penelitian oleh Juniati [7], proses pembacaan tumpukan RFID tag secara bersamaan agar tidak terjadi tabrakan atau collision maka memerlukan penerapan anti-collision sehingga dapat mengatur pembacaan dan penulisan data pada RFID tag. Penelitian yang dilakukan oleh Sandi [8], bahwa memonitor kondisi air tambak pada jarak jauh dapat diakses melalui teknologi Internet Of Thing (IOT) sehingga tidak perlu melihat secara langsung pada tambak. Berikutnya teknologi Internet Of Thing (IOT) berfungsi untuk melakukan monitoring data kunjungan perpustakaan. Terdapat halaman yang akan menampilkan berbagai macam informasi dan data yang terhubung koneksi internet lalu dapat dikelola secara otomatis oleh Khadafi [9].

Berdasarkan perkembangan teknologi saat ini banyak hal yang dikembangkan salah satunya adalah Radio Frequency Identification (RFID), yang digunakan untuk mengidentifikasi suatu objek atau barang. Dan teknologi Internet Of Thing (IOT) dapat digunakan pada berbagai macam bidang dalam kehidupan manusia. Menjadi salah satu konsep peralatan yang terkoneksi internet dalam menangani permasalahan pengendalian jarak jauh oleh Mazeda dan Nasir [10]. Penelitian ini merupakan pengembangan sistem informasi perpustakaan menggunakan perangkat RFID sebagai masukan, mikrokontroler menggunakan NodeMCU sebagai proses dengan IOT untuk mentransfer data melalui jaringan. Terdapat web application development dan web application existing yang dirancang sebagai simulasi sistem manajemen perpustakaan. Penerapan Client URL (CURL) yang berfungsi untuk mengirim dan menerima data melalui URL yang terkoneksi internet. 


\section{DATA DAN METODE}

\section{A. Bahan dan Peralatan Penelitian}

Konsep metode penelitian ini dilakukan melalui observasi, wawancara dan studi literatur. Adapun sumber yang dijadikan sebagai referensi dalam melaksanakan penelitian yaitu buku dan jurnal yang terbaru maupun dari penelitian terdahulu yang terkait. Tahapan penelitian membutuhkan perangkat keras dan perangkat lunak yang akan digunakan untuk penelitian. Adapun perangkat keras dan perangkat lunak yang digunakan sebagai berikut :

1) Perangkat Keras

- Laptop ASUS A455L, processor (Intel ® core $^{\mathrm{TM}}$ i5-4210U CPU @ 1.70GHz 2.40GHz), RAM 8,00 GB, dengan sistem operasi Windows 10 Pro

- RFID RC522 Arduino Reader Write module kit SPI 13,56 MHz Mifarea

- Stiker RFID 13,56 MHz 1 K 30×15mm

- NodeMCU V3 ESP8266

- Micro USB dengan kecepatan transfer 5Gps, output daya 5V dan 1,5A

2) Perangkat Lunak

- Arduino IDE versi 1.8.9

- MySQL

\section{B. Prosedur Penelitian}

Serangkaian kegiatan pada penelitian yang dilakukan secara teratur dan sistematis untuk mencapai tujuan penelitian yaitu sebagai berikut :

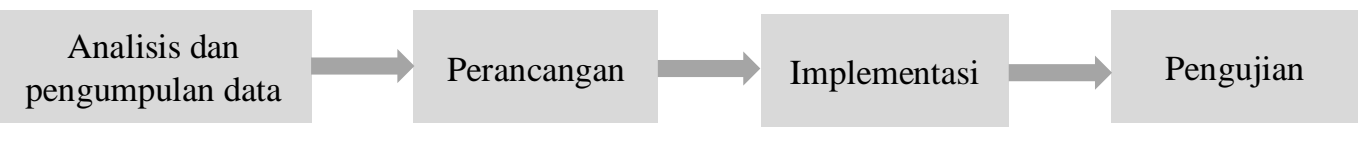

Gambar 1 Prosedur Penelitian

Penelitian dimulai dengan analisis dan pengumpulan data yang diperoleh dari hasil wawancara dengan pihak administrator perpustakaan. Lalu melakukan perancangan bisnis, perancangan alat, dan perancangan antar muka berdasarkan kebutuhan. Kemudian implementasi untuk mengetahui perencanaan dan perancangan sesuai dengan yang diharapkan. Selanjutnya yaitu pengujian apakah alat dan sistem dapat berjalan baik dan sesuai tujuan atau tidak.

C. Blok Diagram

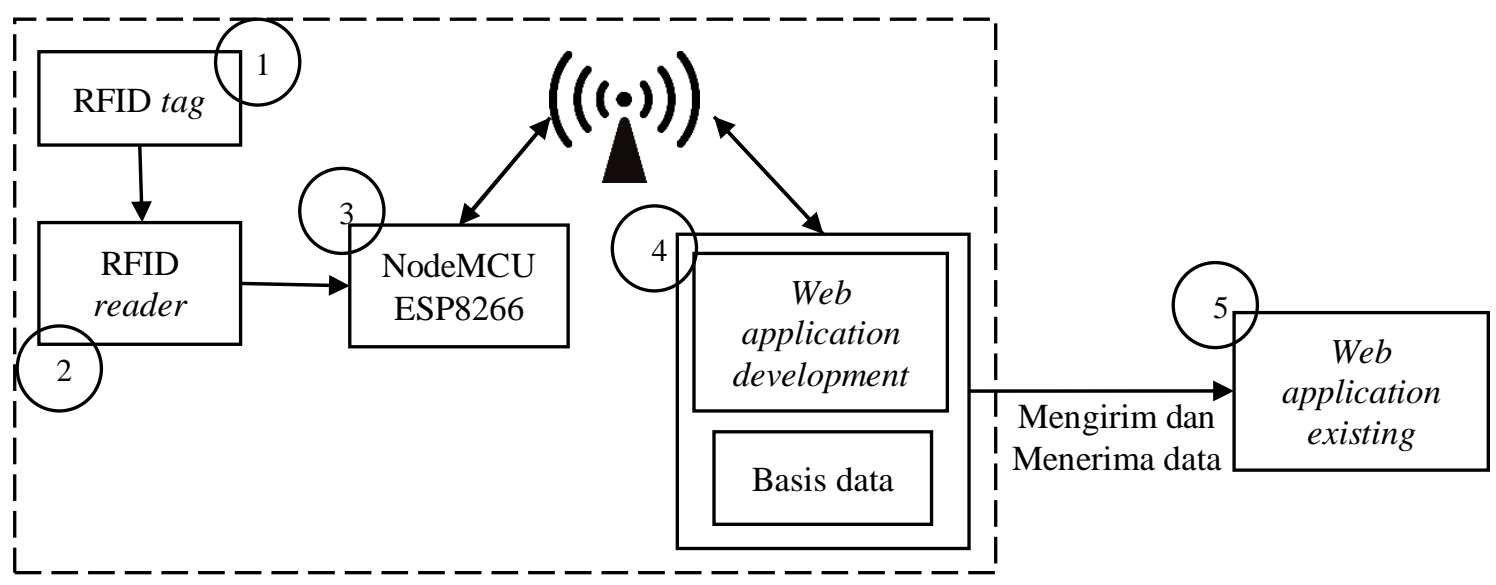

Gambar 2 Blok Diagram

Keterangan :

1. Alat berupa stiker yang akan disematkan pada sebuah objek yaitu buku.

2. RFID reader akan mengidentifikasi atau membaca tag berdasarkan dengan ketentuan.

3. Kemudian salah satu mikrokontroler yang telah dilengkapi modul Wi-Fi ESP8266 yang digunakan yaitu NodeMCU V3 berfungsi membaca dan memproses berdasarkan masukan dari RFID.

4. Selanjutnya aplikasi pengembangan yang dapat diakses web browser yang terkoneksi internet akan menampilkan keluaran. Hasil keluaran berupa menu input buku, proses peminjaman buku dan pengembalian buku, disertai penyimpanan data pada localhost.

5. Lalu terdapat prototipe yang berfungsi sebagai sistem manajemen perpustakaan. 
D. Diagram Alir Perancangan Sistem

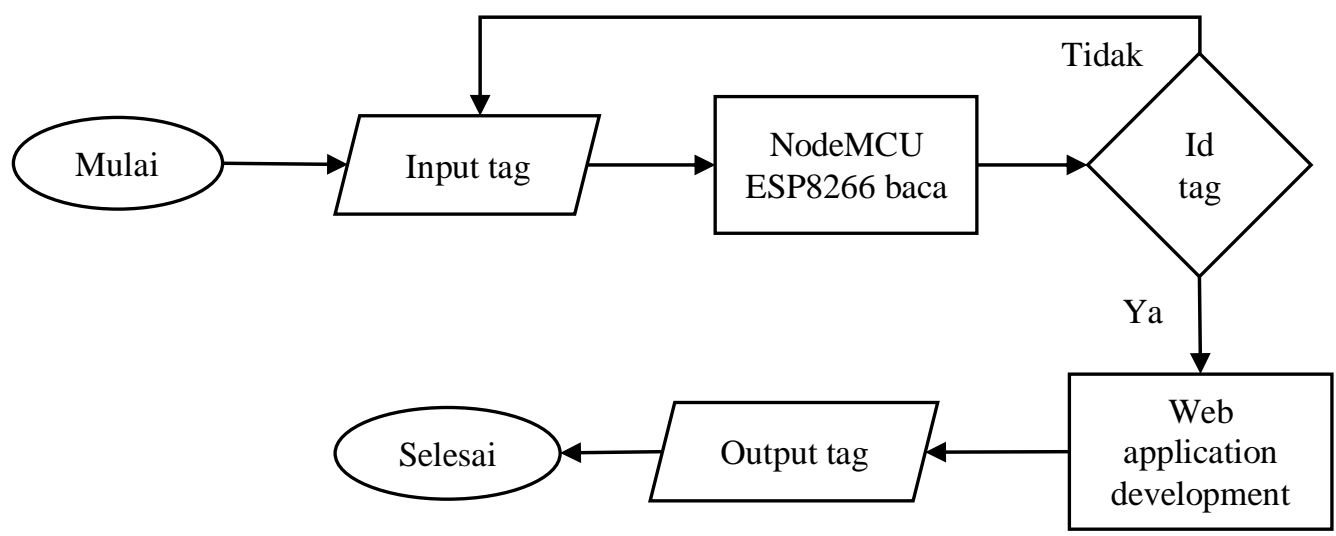

Gambar 3 Diagram Alir Perancangan Sistem

Diagram alir mempunyai proses dengan mulai, lalu input tag yang dilakukan oleh perangkat RFID dan NodeMCU akan melakukan pembacaan. Jika id tag terbaca atau diterima maka web application development sebagai sistem manajemen perpustakaan akan melakukan pekerjaan yang diterima dari perangkat alat. Kemudian menampilkan keluaran dari sistem berupa informasi berdasarkan masukan.

E. Proses Pengujian

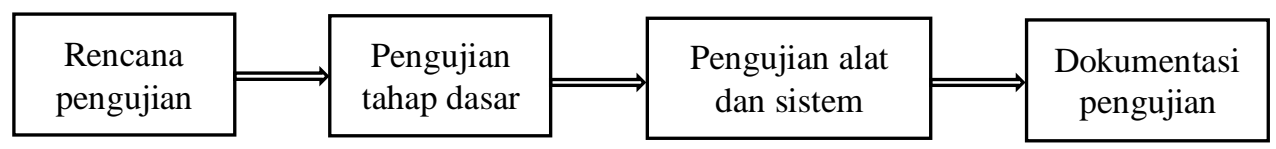

Gambar 4 Proses Pengujian

Kerangka dalam proses pengujian terdiri dari rencana pengujian yang telah dibuat berdasarkan analisis dan pengumpulan data. Lalu pengujian tahap dasar, pengujian alat dan sistem menggunakan metode unit testing. Terakhir yaitu melakukan dokumentasi pengujian berdasarkan tahapan pembacaan pada perangkat alat sampai keluaran pada sistem administrasi manajemen dengan keterangan valid atau tidaknya pengujian yang dilakukan.

\section{HASIL DAN PEMBAHASAN}

Pada bab ini yaitu membahas mengenai perangkat keras dan teknik pengujian menggunakan unit testing yaitu pengujian tahap dasar dari sebuah pembuatan perangkat lunak yang akan dilakukan oleh pengembangnya. Pengujian sistem menggunakan metode black box testing yaitu pengujian terhadap fungsi dari sistem administrasi perpustakaan.

\section{A. Perancangan}

1) Perancangan Pada Sistem Administrasi Perpustakaan

Aliran informasi berupa pesan yang digambarkan melalui proses bisnis pada sistem administrasi perpustakaan. Terdapat proses pendataan buku, peminjaman buku dan pengembalian buku yang akan berjalan pada penelitian ini. Adapun proses BPMN yang dirancang ditunjukkan pada Gambar 5.

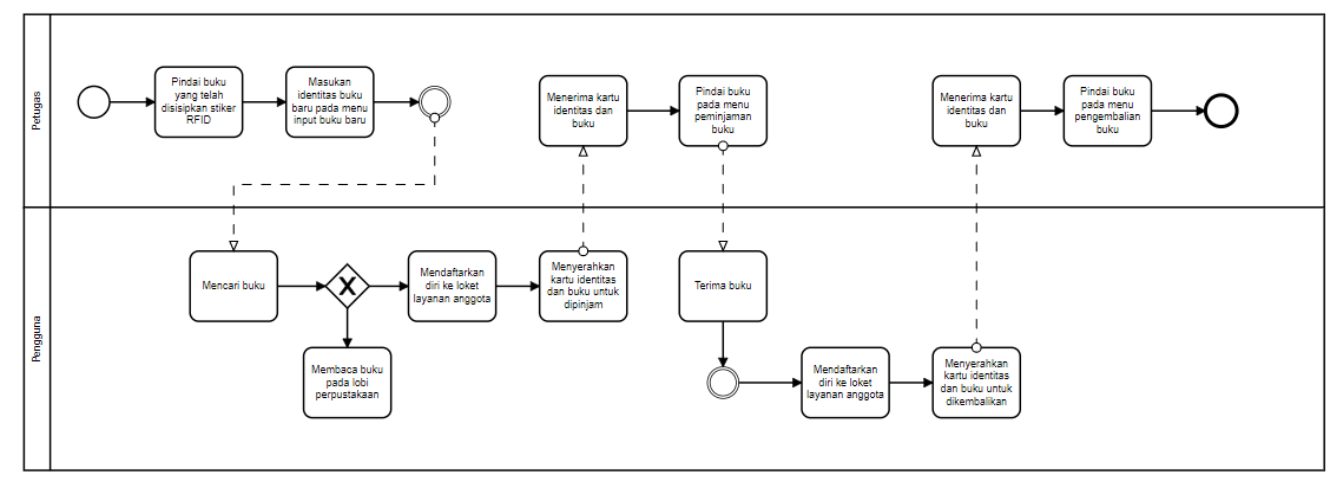

Gambar 5 Proses BPMN Sistem Administrasi Perpustakaan

2) Perancangan Alat

Tahapan ini dilakukan berdasarkan prosedur penelitian dan telah diberikan kode program pada setiap komponen. Blok input sebagai masukan utama yang akan dikirim oleh tag berupa kode unik lalu reader membaca dan memberikan informasi. Blok proses yang dilakukan oleh mikrokontroler sebagai komponen utama untuk mengakses semua blok-blok perintah. Kemudian blok output 
akan menampilkan keluaran berupa hasil yang didapat dari blok input dan blok proses pada aktivitas administrasi perpustakaan . Perancangan alat yang digunakan ditunjukkan pada Gambar 6.

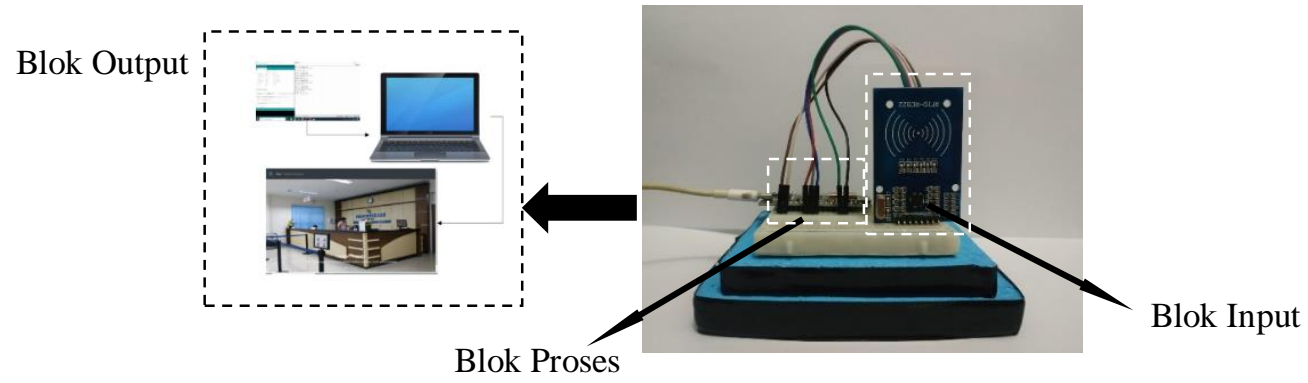

Gambar 6 Perancangan Perangkat Alat

3) Perancangan Antar muka

Perancangan tampilan antar muka pada sistem administrasi perpustakaan menyesuaikan kebutuhan dengan menyediakan metode input-output data. Aplikasi yang dikembangkan yaitu aplikasi sistem administrasi perpustakaan menggunakan perangkat alat RFID dan nantinya akan digunakan oleh administrator perpustakaan.
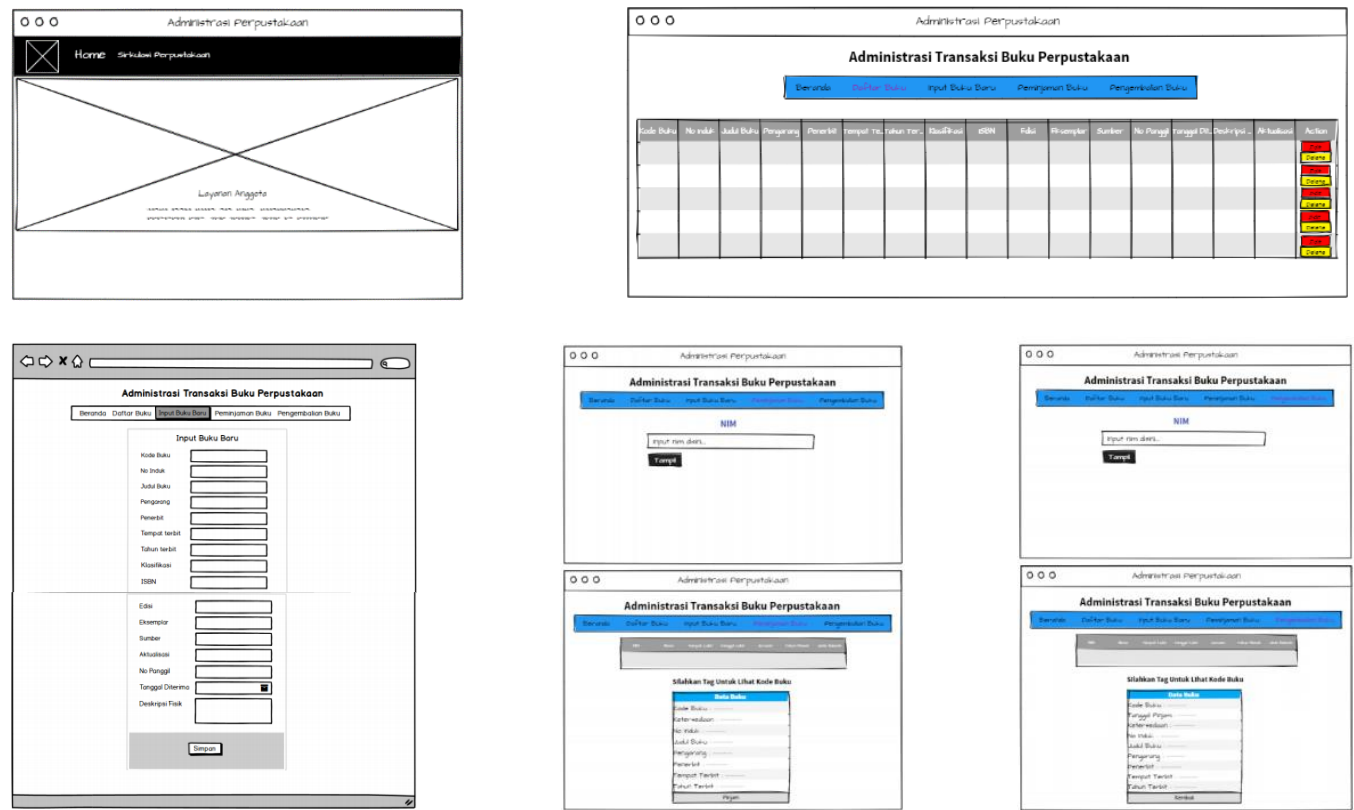

Gambar 7 Tampilan Antar Muka Sistem Administrasi Perpustakaan

\section{B. Implementasi}

Tahap implementasi dilakukan pada penelitian ini yaitu setelah tahap perancangan dimana proses pada prosedur penelitian berjalan berdasarkan perencanaan. Sehingga tahap perancangan dapat diimplementasikan dengan kode program dan dilakukan pengujian untuk memperoleh informasi sesuai dengan tujuan.

\section{Pengujian}

Pembacaan tag dilakukan dengan cara berhadapan langsung dengan pemindai. Berdasarkan pengujian pembacaan sebanyak 18 kali, jumlah berhasil sebanyak 13 kali dan jumlah gagal sebanyak 5 kali. Sehingga tingkat keberhasilan yaitu sebagai berikut :

$$
\text { keberhasilan }(\%)=\frac{\text { jumlah berhasil }}{\text { jumlah pengujian }} x 100=\frac{13}{18} \times 100=72,22 \%
$$

Pengujian alat terhadap sistem dalam melakukan proses input buku baru, peminjaman buku dan pengembalian buku dengan jarak baca 0-4 cm. Pemindaian buku akan dilakukan pada perangkat RFID yang terhubung dengan koneksi internet, dan melakukan proses pada aplikasi pengembangan. Penerapan curl bertujuan untuk mengirim dan menerima data dari web application development dengan web existing.

Tabel 1 Tabel Pengujian Alat Terhadap Sistem Aplikasi Web Pengembangan 
No Skenario Pengujian

1. Masuk tampilan utama

2. Melakukan pemindaian buku baru pada perangkat alat, dan form input buku baru diisi dengan lengkap lalu memilih tombol Simpan

3. Masuk pada menu Daftar Buku

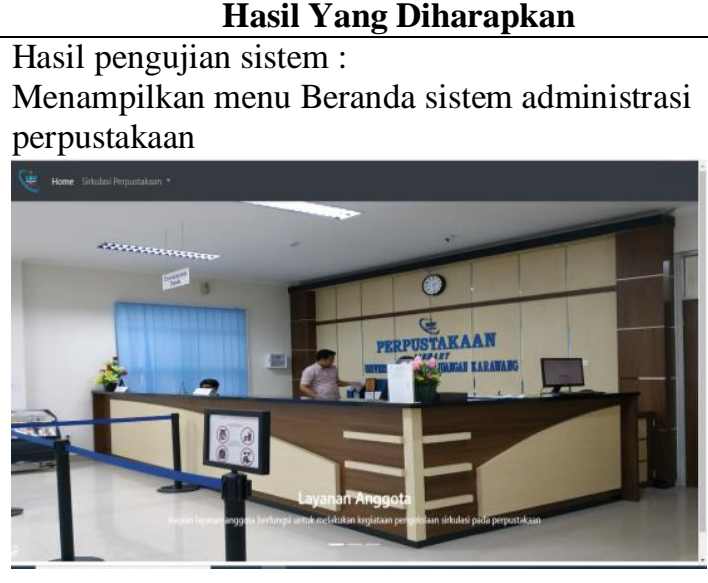

Hasil pengujian alat:

Valid

Perangkat alat berhasil membaca kode unik, dan menampilkan pada kolom Kode Buku

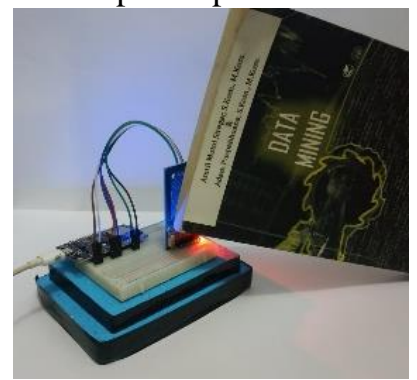

Hasil pengujian sistem :

Sistem berhasil menampilkan form Input Buku Baru, form diisi sesuai deskripsi buku

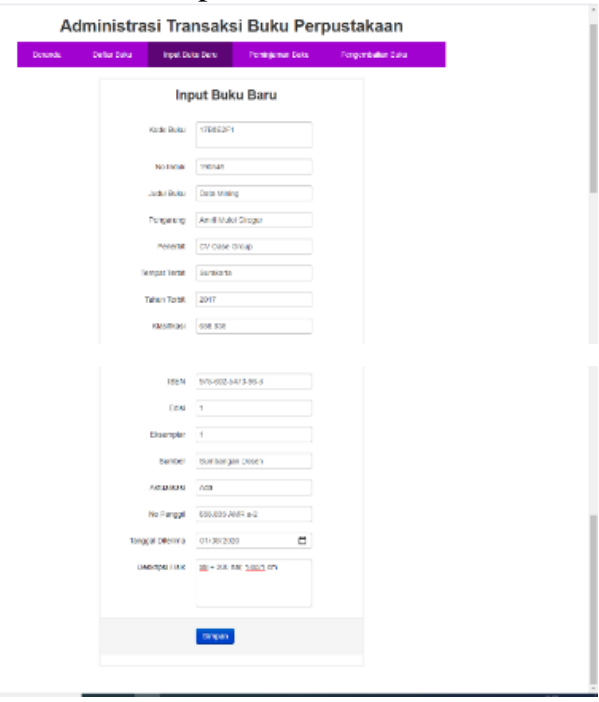

Hasil pengujian alat :
Kesimpulan

Valid

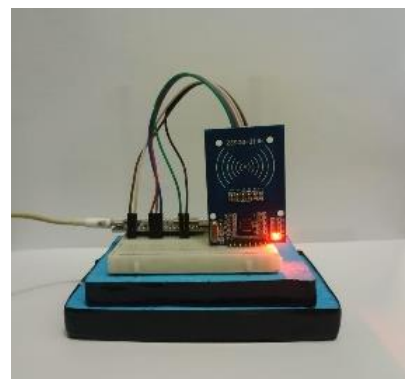

Hasil pengujian sistem : 


\begin{tabular}{llll}
\hline No & Skenario Pengujian & Hasil Yang Diharapkan & Kesimpulan
\end{tabular}

4. Melakukan pemindaian buku untuk proses peminjaman buku
Sistem berhasil menampilkan menu Daftar Buku dan terisi daftar seluruh buku

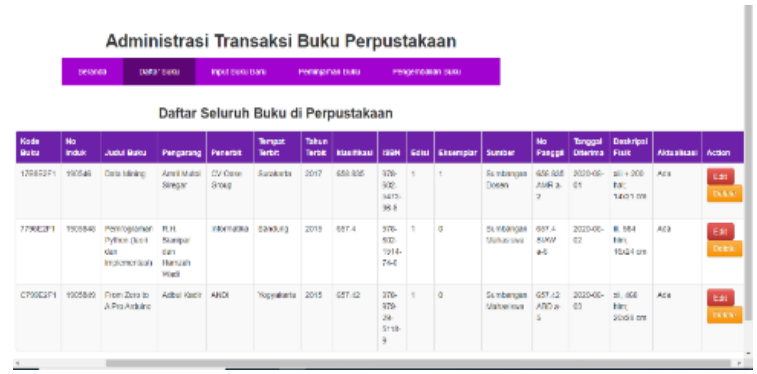

Hasil pengujian alat :

Valid

Melakukan pemindaian buku yang telah disisipkan stiker RFID pada pemindai dengan jarak 0-4 cm

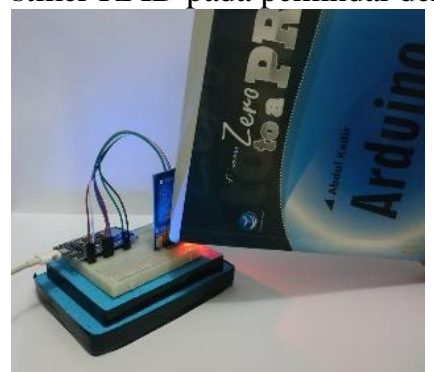

Hasil pengujian sistem :

Sistem berhasil menampilkan data pengguna dan identitas buku secara otomatis

Administrasi Transaksi Buku Perpustakaan

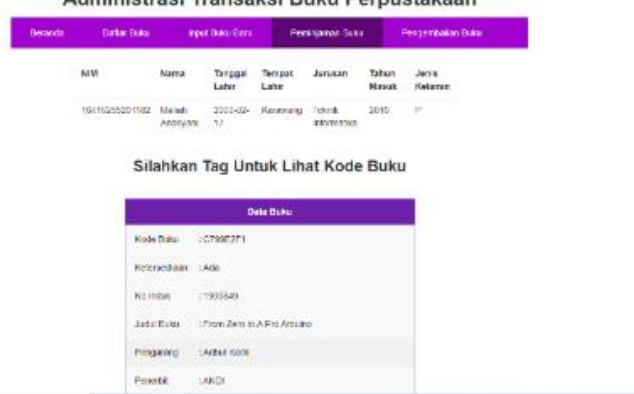

Hasil pengujian alat:

Valid

Melakukan pemindaian buku yang telah disisipkan

stiker RFID pada pemindai dengan jarak 0-4 cm

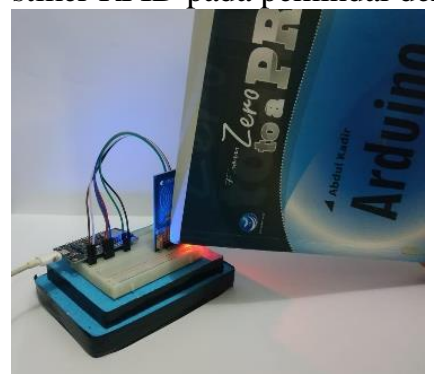

Hasil pengujian sistem :

Sistem berhasil menampilkan data pengguna dan identitas buku secara otomatis 


\begin{tabular}{|c|c|c|}
\hline $\begin{array}{ll}\text { No } & \text { Skenario Pengujian } \\
\end{array}$ & Hasil Yang Diharapkan & Kesimpulan \\
\hline & 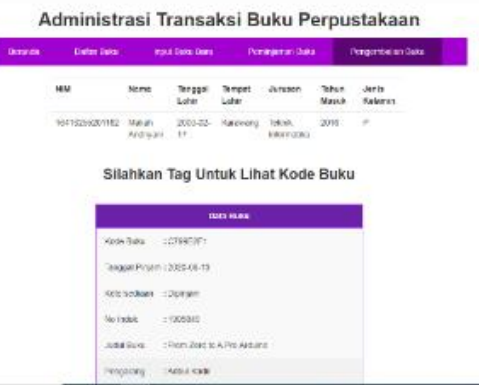 & \\
\hline
\end{tabular}

Tabel 2 Tabel Pengujian Alat Terhadap Sistem Aplikasi Web Existing

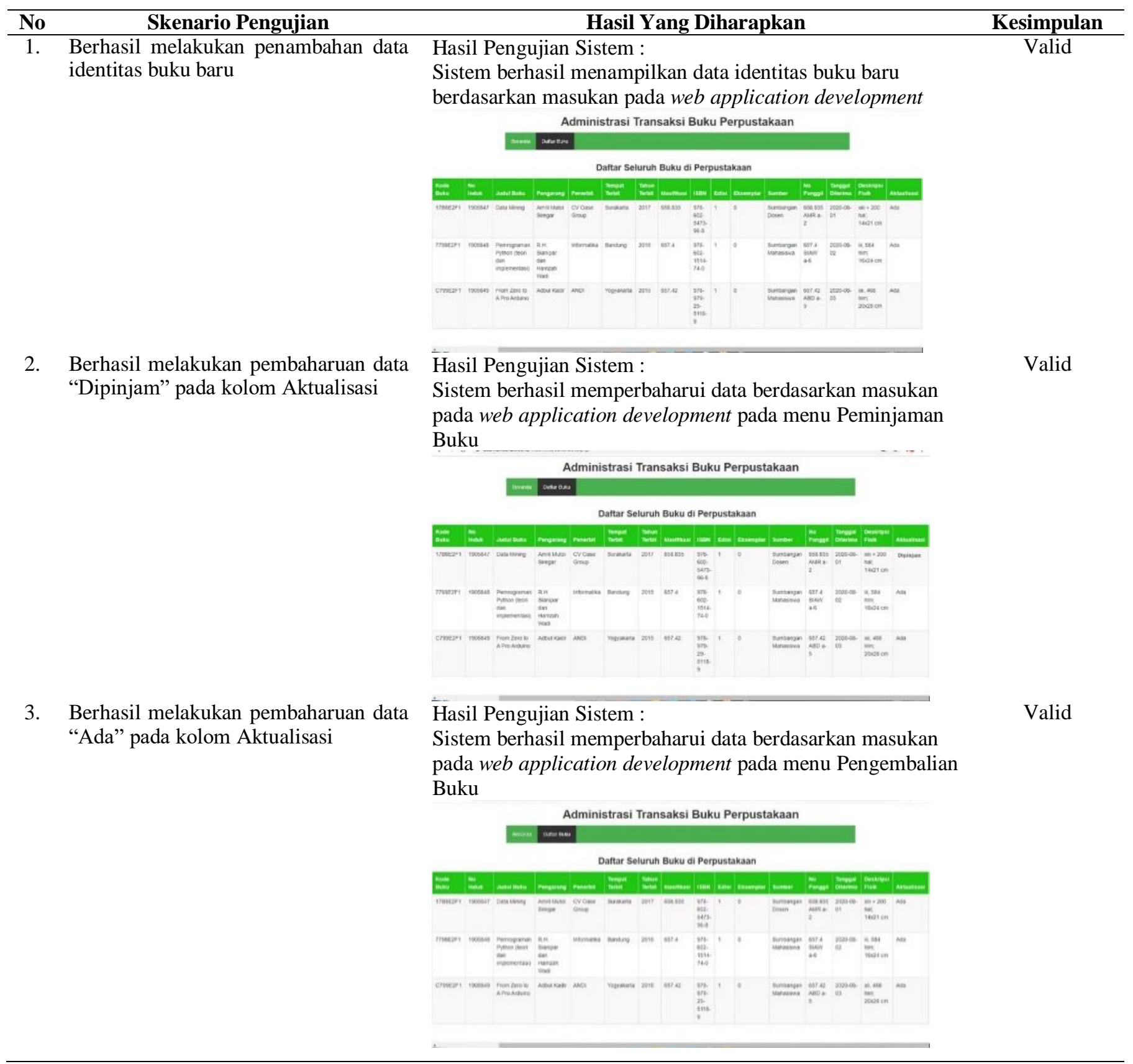


Pengujian pada penelitian yang telah dilakukan berdasarkan aplikasi menggunakan perangkat RFID menghasilkan keluaran berupa informasi dari masukan sesuai dengan tujuan yang diinginkan. Proses pengujian dilakukan bertahap berdasarkan perancangan dengan kode program, memeriksa fungsional dari perangkat lunak, melakukan masukan data dari tampilan aplikasi dengan perangkat alat, memeriksa kesesuaian hasil tampilan pada layar, dan menentukan keluaran yang terbaik.

\section{KESIMPULAN DAN SARAN}

Berdasarkan hasil tahapan penelitian yang telah dilakukan dapat diimplementasikan dan melakukan pengujian, maka dapat disimpulkan bahwa pengujian keberhasilan pembacaan tag model stike pada reader sebesar 72,22\%. Lalu perangkat alat dan sistem berhasil dilakukan dengan baik berdasarkan proses pengujian yang telah dilakukan. Kemudian penerapan metode curl pada aplikasi sistem dapat berjalan baik sebagai penerima dan pengirim data antara dua aplikasi sistem. Sehingga pengembangan sistem informasi perpustakaan dengan teknologi internet of thing menggunakan perangkat radio frequency identification berbasis nodemcu berhasil $100 \%$.

Saran untuk penelitian selanjutnya yaitu melakukan perkembangan perangkat alat reader RFID dengan spesifikasi dapat membaca lebih dari satu tag secara simultan dan jarak jauh. Spesifikasi tersebut dengan bantuan teknologi internet of thing dapat mengembangkan keamanan pada perpustakaan.

\section{PENGAKUAN}

Naskah ilmiah ini adalah sebagian dari penelitian Tugas Akhir milik Maliah Andriyani dengan judul Pengembangan Sistem Informasi Perpustakaan Dengan Internet Of Thing Menggunakan Perangkat Radio Frequency Identification Berbasis NodeMCU, yang dibimbing oleh Jamaludin Indra dan Anis Fitri Nur Masruriyah.

\section{DAFTAR PUSTAKA}

[1] KBBI. (2019). Perpustakaan.

[2] Rahmah, E. (2018). Akses Dan Layanan Perpustakaan (Edisi Pert). Jakarta: Prenadamedia Group.

[3] Aini, N., Wicaksono, S. A., \& Arwani, Issa. (2019). Pembangunan Sistem Informasi Perpustakaan Berbasis Web Menggunakan Metode Rapid Application Development (RAD). Jurnal Pengembangan Teknologi Informasi dan Ilmu Komputer, 3(9), 8647-8655

[4] Angga Primadhasa, Dedi Triyanto, S. (2017). Sistem Manajemen Perpustakaan Menggunakan Radio Frequency Identification (RFID). Jurnal Coding, Sistem Komputer Untan, 05(3), 32-39.

[5] Pratiwi, F., Pangaribuan, P., \& Priramadhi, R. A. (2018). Design of Automatic Book Return System Using RFID. Proceeding f Engineering, 5(3), 4203-4210.

[6] Pratama, I. G. Y., Wicaksono, S. A., \& Saputra, M. C. (2018). Pengembangan Sistem Informasi Manajemen Perpustakaan Pada Ruang Baca Fakultas Ilmu Komputer Universitas Brawijaya. Pengembangan Teknologi Informasi Dan Ilmu Komputer, 2(12), 6669-6678.

[7] Juniati, S. G., Sugesti, E. S., Elektro, F. T., \& Telkom, U. (2019). Anti-Collision Delay Protocol Of RFID Network In The Tokong Nanas Building Telkom University. E-Proceeding of Engineering, 6(1), 511-516.

[8] Susanto Sandi. (2020). Implementasi Fuzzy Logic Pada Tambak Ikan Bandeng Berbasis Internet Of Things (IOT). Scientific Student Journal for Information, Technology and Science, 1(1), 26-32

[9] Khadafi., Winarsih, (2020). Implementasi RFID dan NodeMCU Untuk Data Kunjungan Perpustakaan Berbasi IOT. Jurnal Media Informatika BudiDarma. $4(2), 264-270$

[10] Mazeda \& Nasir. (2019). Perancangan Sistem Rekam Medis Rumah Sakit Menggunakan RFID Berbasis Internet Of Thing. Jurnal Teknologi Rekayasa Informasi dan Komputer. 3(1), 2581-2882 